\title{
Arduino based gas leakage control and temperature monitoring system
}

\author{
Abubakar Yakub Nasir ${ }^{1}$, U. I. Bature ${ }^{2}$, N. M. Tahir ${ }^{3}$, A. Y. Babawuro ${ }^{4}$, Adoyi Boniface ${ }^{5}$ A. M. Hassan ${ }^{6}$ \\ ${ }^{1,2,5,6}$ Department of Computer and Communications Engineering, Abubakar Tafawa Balewa University, Nigeria \\ ${ }^{3,4}$ Department of Mechatronics and systems Engineering, Abubakar Tafawa Balewa University, Nigeria
}

\begin{tabular}{l} 
Article Info \\
\hline Article history: \\
Received Nov 12, 2019 \\
Revised Jan 20, 2020 \\
Accepted Feb 2, 2020 \\
\hline
\end{tabular}

Keywords:

Gas leakage

GSM

LCD

LPG

MQ

\begin{abstract}
In the wake of the sudden replacement of wood and kerosene by gas cookers for several purposes in Nigeria, gas leakage has caused several damages in our homes, Laboratories among others. installation of a gas leakage detection device was globally inspired to eliminate accidents related to gas leakage. We present an alternative approach to developing a device that can automatically detect and control gas leakages and also monitor temperature. The system detects the leakage of the LPG (Liquefied Petroleum Gas) using a gas sensor, then triggred the control system response which employs ventilator system, Mobile phone alert and alarm when the LPG concentration in the air exceeds a certain level. The performance of two gas sensors (MQ5 and MQ6) were tested for a guided decision. Also, when the temperature of the environment poses a danger, LED (indicator), buzzer and LCD (16x2) display was used to indicate temperature and gas leakage status in degree Celsius and PPM respectively. Attension was given to the response time of the control system, which was ascertained that this system significantly increases the chances and efficiency of eliminating gas leakage related accident.
\end{abstract}

This is an open access article under the CC BY-SA license.

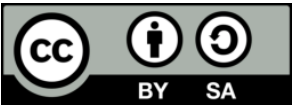

Corresponding Author:

Abubakar Yakub Nasir,

Department of Computer and Communications Engineering,

Abubakar Tafawa Balewa University,

P.M.B 0248, Bauchi, Nigeria.

Email: aynasir@gmail.com

\section{INTRODUCTION}

Nowadays, in Africa the use of kerosene stove and/or electric cooker is rapidly replaced by the gas cooker which is abundant and more cost effective for domestic use. Gas is also used in laboratories and industries for various purposes also used in some vehicles as a fuel due to hiking prices of diesel or petrol [1]. LPG are usually stored in a compressed air tight steel vessels that are meant to be at room temperature [2], or even less to prevent explosion.

Some researchers mentioned that LPG leakage has become one of the most concern issues these days. Several reports show that some fire incidences could have been avoided in the past if gas leakages were detected. Consider the recorded world's worst gas accident at Bhopal gas tragedy in India that happened as a result of gas leakages [3]. Therefore, going by the growing level of patronage of LPG for domestic and industrial applications, it become necessary to come up with an alternative safety measures and process for catering the outbreak of fire accident that may be as a result of leakages [4]. It was detailed before the creation of domestic gas detectors in the beginning of $90 \mathrm{~s}$, that the use of chemically infused paper that changes colour under the influences of gas was appreciated to detect the presence of LPG [5]. Quite a 
number of effective gas leakages systems were developed after the emergence of electronic gas detectors. Also, considering the evolvement of 5G wireless communication, in 2018 [6] V. R. Nag and M. Sarvagya mentioned that dual band printed slot antenna that can greatly assist in realizing advancement in communication. Thus, wireless communication could aid in detecting and alerting danger before they occur [7-9]. Notification system is another form of alert; this process will allow home owners to receive messages before dangers occur [10]. In [11], they proposed an architecture of an alerting system that can cater for the setbacks of website, bulletin boards and social media. Hence, it become necessary to design systems that can detect and alert owners for quick measures before harm transpire.

\section{PREVIOUS WORK}

Safety system is essential; it acts as a security measure against harm or damage. Smoke and gas sensors, fire alarm and temperature sensors are considered as counter measures for fire incident. Air contaminated with harmful gases usually oxides of carbon, nitrogen and sulphur could endanger living beings and organisms such as difficulty in breathing, stress, skin disorder and often end up in fire incidences. Thus, it is pertinent to carter for the causes of air pollution before it causes some harms. So many monitoring systems were proposed because of their importance, ranging from human monitoring using biosensors [12], Temperature and humidity monitoring at bio-energy process [13], suspicious human activities detection system [14] and [15] for Gas leakage detection using LabVIEW display. In 2019, method of detecting air pollution using image processing techniques was proposed [16] using infrared image. Temperature control systems are becoming common in almost all fields and households because of their importance. An automatic multi appliances temperature dependent value was proposed in [17], the system helps in reducing reliance on human operator in warehouses, industries, laboratories etc. In [18], A. A. Asraf Roslan and R. Baharom have proposed a gas leakage, fire and power supply failure monitoring system, it consists of GSM module and Arduino UNO that provides some features like smoke and gas detectors that send a notification in form SMS with the location and particular incident, this could be quickly responded to before any disaster occur, but our system detect the concentration of the gas and the level of the temperature and send SMS immediately when the threshold exceed some certain level.

As a result of sudden development witnessed in communication sector in most of developing countries, GSM-Based gas monitoring system has received huge interest. A microcontroller based gas leakage detector system was designed in [19], after MQ5 senses the presences of the gases, an SMS will be sent to the owner's phone via GSM module controlled by the brain of the system (PIC16F877), but alarm using buzzer will be activated as a third party environmental control of the system. Also, another GSM-Based gas detector system was developed in [20], this possess better accuracy than [19] but it requires an external pre-control intervention for the environment, uses MQ-6 gas sensor with AT89C51 microcontroller. Similarly, another approach using DS18B20 temperature sensing unit, humidity sensing using db171 and carbon dioxide using b530 unit was developed [21], the brain of the system was the STC89C51RC microcontroller unit, and the system was effective but a little bit expensive and complex. An IoT based house security system was proposed in [22], this system has the ability to sense and detect gas, motion, temperature and humidity using Arduino and Raspberry Pi and it has an ability to send messages to the house owner in case of any suspicious act, but the use of servo motor that moves the camera for motion capture may add unnecessary cost and source of error to the device. Another IoT based system was proposed in [23], the system consists of control and sensor units for managing the received data.

The NodeMCU development kit was employed as the core control unit, this system provides gas and temperature sensing and a buzzer was used for alerting the house occupant in case of danger issues, but the use of NodeMCU development kit as core control unit may add cost to the system. Another device that has the ability to make three different actions when LPG gas was detected was proposed [24], it alert the owner by making sound as a notification for quick action, send an SMS to a phone and finally provide a display on a screen. Despite being cost effective; the system cannot detect temperature which is vital when it comes to fire disaster control. This project is built on GSM based monitoring system that utilizes the effective semiconductor gas sensor (MQ-6), it has the capacity to sense various natural gases not only butane and propane using tin dioxide $\left(\mathrm{SnO}_{2}\right)$. The GSM module that requires one SIM card from any network, this will be used for sending messages to the user's cell phone after a gas leakage detected by the sensor. The basic humidity and digital temperature sensor DHT 22 measures the surrounding air and passes the digital signal to the UNO Arduino data pin, it requires no analog input. This makes the design cost effective, efficient and also environmentally friendly. 


\section{RESEARCH METHOD}

\subsection{Block diagram}

The proposed gas leakage security system is illustrated in Figure 1.

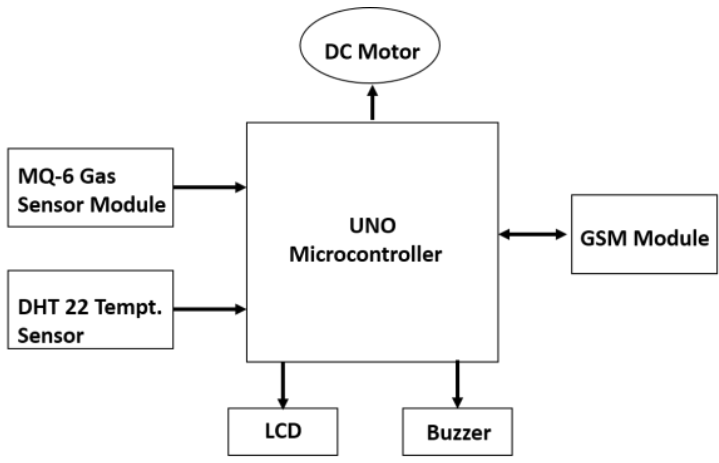

Figure 1. Block diagram

\subsection{MQ-6 Gas sensor}

This type of gas sensor is shown in Figure 2. Is a class of gas leakage sensor which is manufactured from a semiconductor material with tin dioxide $\left(\mathrm{SnO}_{2}\right)$ as the sensitive part. In clean air, it has a very low conductivity. It has sensitivity to propane, butane and other natural gases with low sensitivity to alcohol and cigarette smoke. Also, this type of gas sensor can be used for the detection of combustible gases such as methane.

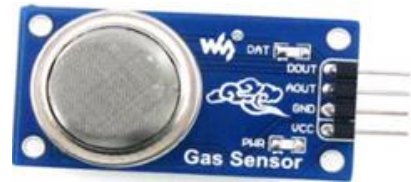

Figure 2. MQ-6 Gas sensor

The sensor has a concentration range of 300-1000ppm with fast response time. The sensor has six (6) pins. Four (4) pins are used for signals fetching and the other two (2) for providing heating current. Figure 3 shows the typical sensitivity characteristics of this type of gas sensor (MQ-6).

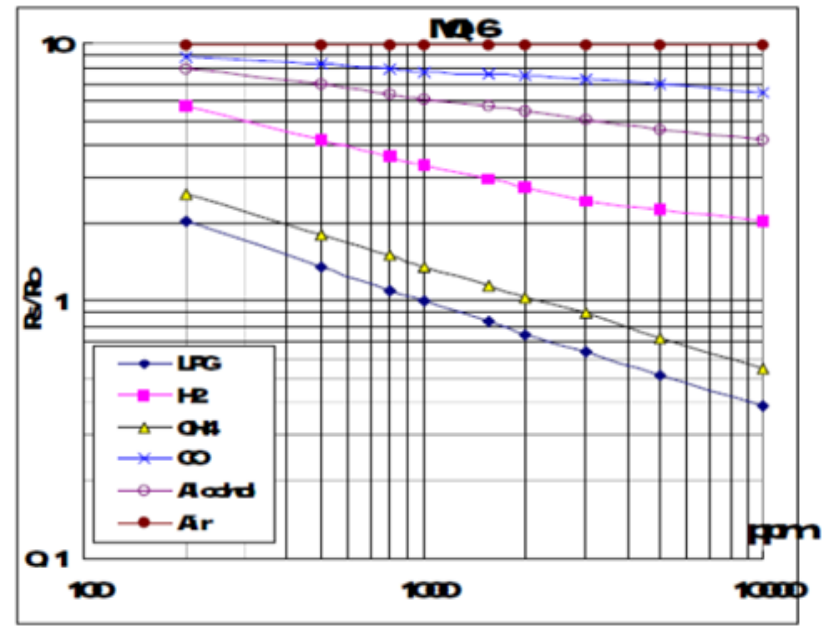

Figure 3. Sensitivity characteristics of the MQ-6 gas sensor for several gases 


\subsection{GSM receiver}

The Arduino UNO microcontroller hardware was programmed to send to the user SMS notification via the GSM module (shown in Figure 4) whenever gas leakages are detected by the gas sensor. The GSM module uses a single SIM card which connects to any available network (depending on the particular service provider the user decides to use). The module has unique identification number such as those used in mobile phones and work on 12V DC supply. Both SMS and voice messages can be sent via this module which are at the same time saved on the memory space of the microcontroller. The system works in such a way that multiple notifications (in either SMS or voice messages) can be send to police, fire men or the user.

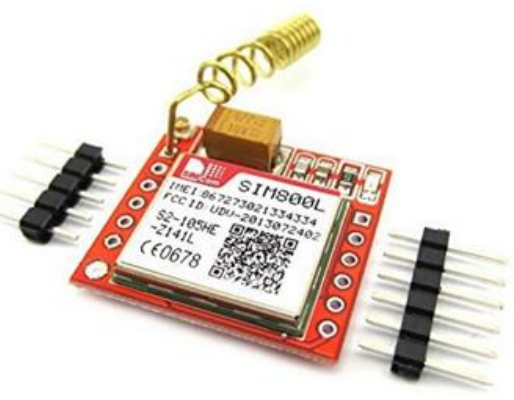

Figure 4. GSM module

\subsection{DHT 22 temperature sensor}

This is a digital type of sensor used for detection of both temperature and humidity (see Figure 5). It uses a thermistor and capacitive humidity to measure the surrounding air and gives out digital signals through the data pin. This sensor doesn't require any analog input pin.

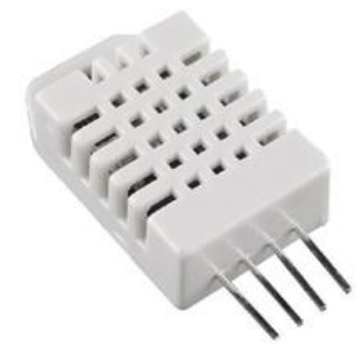

Figure 5. DHT 22 Temperature sensor

\subsection{DC motor}

DC motor is the actuating device used in this work to access the system prototype. It is a rotary type electrical machine that receives a low power electrical signal from the microcontroller and produce mechanical motion.

\section{RESULTS AND DISCUSSION}

In other to obtain a guided decision, two prototypes of the gas leakage and temperature monitoring system were developed. This systems were developed to observe the performance of each setup based on the choice of component used and suggest what system is best for the environment the experiment was carried out. One of the versions of the system [25] uses MQ-6 gas sensor while the newer system utilizes MQ-5. In many similar projects for gas leakage detection, the MQ-series sensors have been tried separately with different microcontroller setup like in [6] they explained the strength and weakness of the MQ-2 sensor when stretch to limit. Meanwhile in [26] MQ-9 was used to test LPG leakage, drawing attension to detection time and concentration of the gas, the project uses only alarm as the means of alert.

In our work we incorporate three monitoring and one control devices while utilizing two diffirent sensor types, we aim to focus on time detection with respect to distance and finally to the delay in response 
of the control system as shown in the graphs (Figure 6) below. The evaluation begins in a chemical Laboratory where substantial amount of heating is performed using Propane Gas Cylinder, this serve as our testing environment. The systems were tested by bringing a propane gas cylinder close to the sensors and continue to vary the distance while data are being collected to observe the detection time and distance. The time and distance were measured using stop watch and meter rule respectively. The data for the time of response of the monitoring unit were also observed using different stop Watch and recorded as shown in the graph below. The sensor detects the LPG gas and sends a signal to the microcontroller, it then analyses the received signal. After that, the microcontroller sends an active signal to other externally connected devices, as a result, a buzzer rings which indicate the presence of the gas. Simultaneously the DC motor opens the ventilation windows and the GSM module send an SMS to a designated mobile phone. Also, when a high temperature is detected using the DHT22, it sends an active signal to the microcontroller and a message is displayed on the LCD screen showing the temperature reading. Upon intervention, when the reset button is pressed, the system refreshes itself and whole system regains a position we refer as the initial state.

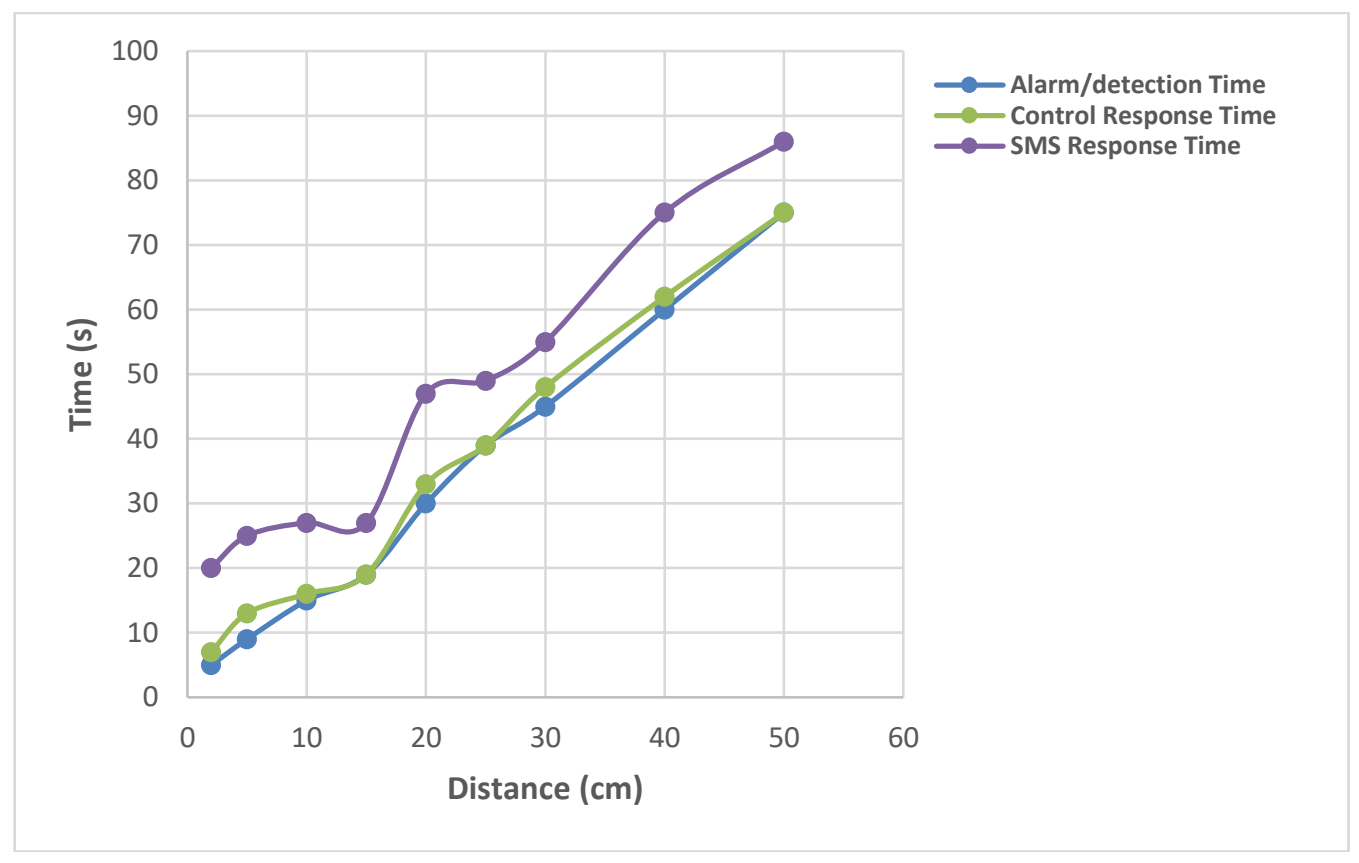

Figure 6. The graph of Gas Alarm/detection response, SMS alert response and ventilation control response time.

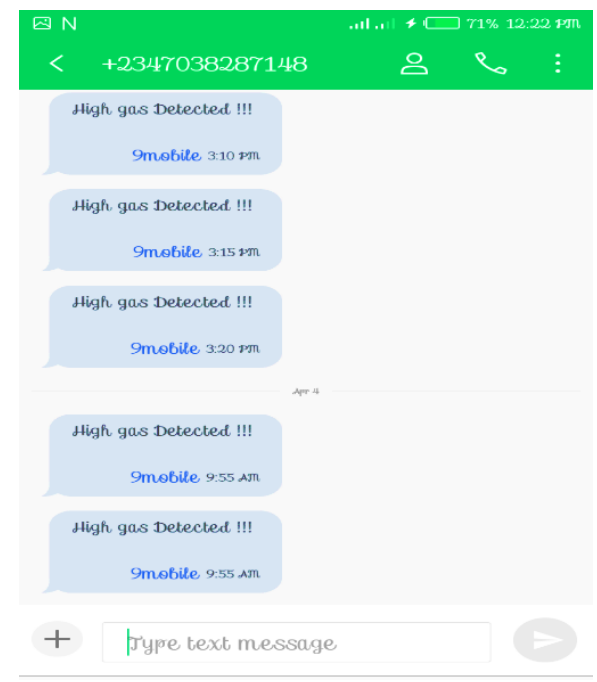

Figure 7. Output message received over a range of test time. 
The system was tested for 20 minutes as shown on Figure 7 and also at different days. During the test, in order to obtaind near accurate timing the team use different stop watch to monitor the Alarm/detection time, the Control response time and the SMS alert time over the varying distance use. Although the only entity that depends on the distance is the Alarm/detection time, the remaining actively rely on the detection signal as indicated in the graph (Figure 6). A Significant delay was seen for the SMS alert time while difficulties were experienced between recording the detection time and control response time, as in many cases the relay is triggered within seconds of detection time. This performance was also noticed with the second system setup as the only difference was the sensor but in future work, in other to get a better judgement, a complete setup change will be considered. Due to similarities recorded in the reading between the two sytems the result of a single system was resolved to be displaced as shown in the graph (Figure 6). In the graph it can be observe that the instability arises mostly from the SMS alert time but overall, the time interval is acceptably fast.

\section{CONCLUSION}

There are several gas leakage control systems in existance today and each address or focused on a particular way of providing solution to the common problem. In other to contribute to this long disturbing problem, a careful analysis was carried out to identify the little gray area in the previously proposed designs. The three monitoring and one control device incorporated enable it to address the delay in response time by automatic quick air control before the intervention of a personal despite being alerted using SMS. This idea reduces heavily the reliance on the action of a personal and increase the window of oppurtunuty to avert disaster. In many similar designs like ours; Despite being cost effective; the system is not design to reduce the concentration of the gas by using air control system and that is what our system successfuly incorporated with good response time of the ventilator. This project is built on GSM based monitoring system that utilizes the effective semiconductor gas sensor (MQ-6), it has the capacity to sense various natural gases not only butane and propane using tin dioxide $\left(\mathrm{SnO}_{2}\right)$. Mainly this device is design to alert with a sound, SMS, provide a display on a screen and finaly control a ventilator. It requires no analog input, which makes the design cost effective, efficient and also environmentally friendly. In our work we focused on time of gas detection with respect to distance and the delay in response of the control system, at the end our design shows an acceptable efficiency. In our future work, we aim to calibrate the gas sensor for a specific gas to be sensed by training instead of the numerous gases it senses.

\section{ACKNOWLEDGEMENTS}

This work is supported by the Department of Computer and Communications Engineering, Abubakar Tafawa Balewa University (ATBU). The authors also thank the Chemical Engineering Laboratory of ATBU.

\section{REFERENCES}

[1] Muller, C., \& Yan, H., "Household fuel use in developing countries: Review of theory and evidence," Energy Economics, vol. 70, pp. 429-439, 2018

[2] S. S. Binti Sarnin, et al., "Liquefied petroleum gas monitoring and leakage detection system using nodemcu ESP8266 and wi-fi technology," Indonesian Journal of Electrical Engineering and Computer Science (IJEECS), vol. 17, no. 1, vol. 166-174, 2020.

[3] Beheshti, M. H., Dehghan, S. F., Hajizadeh, R., Jafari, S. M., \& Koohpaei, A., "Modelling the Consequences of Explosion, Fire and Gas Leakage in Domestic Cylinders Containing LPG," Annals of Medical and Health Sciences Research, 2018.

[4] Dalaba, M., Alirigia, R., Mesenbring, E., Coffey, E., Brown, Z., Hannigan, M., ... \& Dickinson, K. L., "Liquified Petroleum Gas (LPG) Supply and Demand for Cooking in Northern Ghana," EcoHealth, vol. 15, no. 4, pp. 716-728, 2018.

[5] Nuga, O. O., Amusa, K. A., \& Olanipekun, A. J., "GSM-Based Gas Leakage Detection and Alert System," Electrical and Electronic Department, College of Engineering, Federal University of Agriculture, Abeokuta, 2017.

[6] Vibha R. N., Mrinal S., "Review Paper on Different Dual Band Printed Slot Antenna for 5G Wireless Communication," International Journal of Informatics and Communication Technology (IJ-ICT), vol. 7, no. 3, pp. 105-110, 2018.

[7] Swedika Sharma, "A state of art on energy efficient multipath routing in wireless sensor networks," International Journal of Informatics and Communication Technology (IJ-ICT), vol. 7, no. 3, pp. 111-116, 2018.

[8] Marotkar, D. S., \& Yeshwantrao, P. L. Z., "Microstrip Antenna with Photographic Paper Substrate for WLAN," International Journal of Informatics and Communication Technology (IJ-ICT), vol. 7, no. 2, pp. 67-70, 2018. 
[9] Keshamoni, K., "Design and architecture of wireless body area network using android application," International Journal of Informatics and Communication Technology (IJ-ICT), vol. 8, no. 2, pp. 71-76, 2019.

[10] Panjaitan S D, Fratama N, Hartoyo A, Kurnianto R., "Telemonitoring Temperature and Humidity at Bio-energy Process using Smart Phones," TELKOMNIKA (Telecommunication Computing Electronics and Control), vol. 14, no. 2, pp. 762-771, 2016.

[11] Heryati, A., Yulianti, E., Sartika, D., Saluza, I., \& Sanmorino, A., "The design of smart notification on android gadget for academic announcement," TELKOMNIKA (Telecommunication Computing Electronics and Control), vol. 17 , no. 1 , pp. 147-152, 2019.

[12] Hemavathy R. M., PC Kishore Raja, "Monitoring Biosensors and obtaining Data using Gsm Module," International Journal of Informatics and Communication Technology (IJ-ICT), vol. 5, no. 2, pp. 89-88, 2016.

[13] Ng, W. J., \& Dahari, Z., "Enhancement of real-time IoT-based air quality monitoring system," International Journal of Power Electronics and Drive Systems (IJPEDS), vol. 11, no. 1, pp. 390-397, 2020.

[14] J L Mazher Iqbal, and S. Arun, "Intelligent Information System for Suspicious Human Activity Detection in Day and Night," International Journal of Informatics and Communication Technology (IJ-ICT), vol. 7, no. 3, pp. 117-123, 2018.

[15] Yan, H. H., \& Rahayu, Y., "Design and development of gas leakage monitoring system using arduino and zigbee," Proceeding of The Electrical Engineering Computer Science and Informatics, vol. 1, no. 1, pp. 207-212, 2014.

[16] Sulistiyanti, S. R., Setyawan, F. A., \& Komarudin, M., "Detection air pollution based on infrared image processing," TELKOMNIKA (Telecommunication Computing Electronics and Control), vol. 17, no. 4, pp. 1796-1802, 2019.

[17] Jahlool, J. S., "Design and simulation of automatic temperature control and alert system based PIC16F887," APTIKOM Journal on Computer Science and Information Technologies, vol. 2, no. 2, pp. 77-85, 2017.

[18] A. A. Roslan and R. Baharom, "Advanced gas leakage, fire and power supply failure monitoring system," Int J Pow Elec \& Dri Syst (IJEECS), vol. 17, no. 1, pp. 222-227, 2020.

[19] Banik, A., Aich, B., \& Ghosh, S., "Microcontroller based low cost gas leakage detector with SMS alert," In 2018 Emerging Trends in Electronic Devices and Computational Techniques (EDCT), pp. 1-3, 2018.

[20] Shrivastava, A., Prabhaker, R., Kumar, R., \& Verma, R., "GSM based gas leakage detection system," International Journal of Emerging Trends in Electrical and Electronics (IJETEE), vo. 3, no. 2, 2013.

[21] Huang, H., Bian, H., Zhu, S., \& Jin, J., "A greenhouse remote monitoring system based on GSM," In 2011 International Conference on Information Management, Innovation Management and Industrial Engineering, IEEE., vol. 2, pp. 357-360, 2011.

[22] Qasim, H. H., Hamza, A. E., Ibrahim, H. H., Saeed, H. A., \& Hamzah, M. I., "Design and implementation home security system and monitoring by using wireless sensor networks WSN/internet of things IOT," International Journal of Electrical and Computer Engineering (IJECE), vol. 10, no. 3, p. 2617, 2020.

[23] Jaber, A. A., Al-Mousawi, F. K. I., \& Jasem, H. S., "Internet of things based industrial environment monitoring and control: a design approach," International Journal of Electrical \& Computer Engineering (IJECE), vol. 9, no. 6, pp. 4657-4667, 2019.

[24] Kareem, H., "Embedded real-time system for detecting leakage of the gas used in iraqi kitchens," Indonesian Journal of Electrical Engineering and Computer Science (IJEECS), vol. 14, no. 3, pp. 1171-1176, 2019.

[25] Nasir, A. Y., Adoyi Boniface, A. M. Hassan, and N. M. Tahir. "Development of a Gas Leakage Detector with Temperature Control system," Journal of Multidisciplinary Engineering Science and Technology (JMEST), vol. 6, no. 12, pp. 4, 2019.

[26] Mahmood, Sarmad Nozad, Asnor Juraiza Ishak, and Salam T. Hussain, "GSM based gas leak monitoring system," Periodicals of Engineering and Natural Sciences, vol. 7, no. 2, pp. 670-678, 2019. 


\section{BIOGRAPHIES OF AUTHORS}

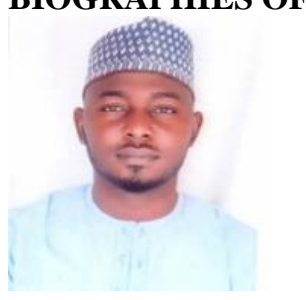

Abubakar Yakub Nasir received a B.Eng. Computer Engineering from Bayero University Kano (BUK), Nigeria and Master of Engineering (Electrical-Computer and Microelectronic system) from Universiti Teknologi Malaysia (UTM), Malaysia. He is currently a lecturer in the Department of Computer and Communications Engineering, Abubakar Tafawa Balewa University Bauchi (ATBU), Nigeria. His research interest includes Computer and Robotic Vision, Image processing and Embedded systems.

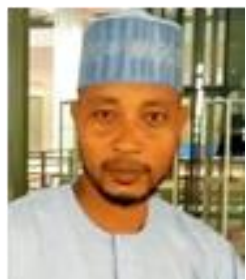

U. I. Bature is currently a $\mathrm{PhD}$. Candidate in the Department of Electrical Engineering, Universiti of Teknologi Petronas (UTP) Malaysia. He received a B.Eng. Computer Engineering from Bayero University Kano (BUK), Kano city, Nigeria and degree of Master of Engineering (Electrical - Computer and Microelectronic system) from Universiti Teknologi Malaysia (UTM), Skudai, Johor Bahru, Malaysia. He is currently a lecturer in the Department of Computer and Communications Engineering, Abubakar Tafawa Balewa University Bauchi (ATBU), Nigeria. His research interest includes Image processing, Nano-material design, embedded systems and Biomedical Systems

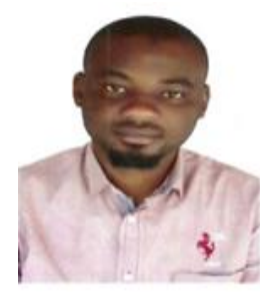

N. M. Tahir received the B.Eng. degree in Electrical Engineering from Bayero University, Kano in 2012 and M.Eng. Degree in Mechatronics and Automatic Control from the UniversitiTeknologi Malaysia in 2016. He has been involved in research at Mechatronics systems and Robotics Laboratory in UniversitiTeknologi Malaysia on vibration control, robotics and Mechatronics system design. He has been a lecturer at the Department of mechatronic and system Engineering, Abubakar Tafawa Balewa University, Bauchi Nigeria since 2014.His main research interests include Vibration Control, Mechatronics Systems Design, Control System Design and Robotics.

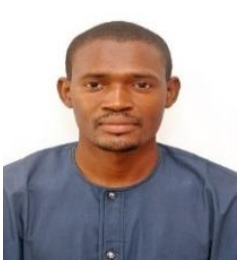

A. Y. Babawuro received a B. Eng. Mechanical Engineering from University of Maiduguri, Borno State, Nigeria and Master of Science (Mechatronics Engineering) from International Islamic University Malaysia (IIUM), Malaysia. He is currently a full-time teaching staff in the Department of Mechatronics and Systems Engineering, Abubakar Tafawa Balewa University Bauchi (ATBU), Nigeria. His research interest includes Robotics and Automation, Active force control, Artficial Intelligence and Machine Learning.

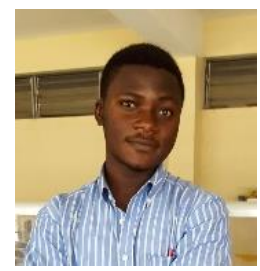

Adoyi Boniface received a B. Eng degree in Computer and Communications Engineering from Abubakar Tafawa Balewa University, Bauchi. He has been involved in research related to electronics and embedded syatems and his research interest includes automation, microelectronics and computer vision.

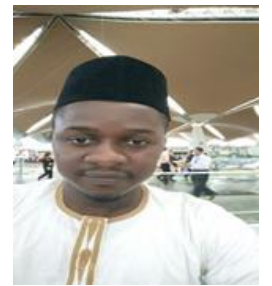

A. M. Hassan is a lecturer with the Department of Computer and Communications Engineering, Abubakar Tafawa Balewa University Bauchi (ATBU), Nigeria. Rececived B.Eng. Computer Engineering from Bayero University Kano (BUK), Kano city, Nigeria and Master of Engineering (Electrical - Computer and Microelectronic system) from Universiti Teknologi Malaysia (UTM), Skudai, Johor Bahru, Malaysia. He is currently a PhD. student in the Department of Electrical Engineering, Bayero University Kano (BUK), Kano. His research interest includes Computer vision, video and image processing, Medical imaging. 